\title{
First-principles study of $\mathrm{Li}$-ion distribution at $\gamma$ - $\mathrm{Li}_{3} \mathrm{PO}_{4} /$ metal interfaces
}

\author{
Koji Shimizu $\odot,{ }^{1,}{ }^{*}$ Wei Liu, ${ }^{1}$ Wenwen $\mathrm{Li},{ }^{2}$ Shusuke Kasamatsu, ${ }^{3,4}$ \\ Yasunobu Ando, ${ }^{2}$ Emi Minamitani, ${ }^{1,5}$ and Satoshi Watanabe ${ }^{1, \dagger}$ \\ ${ }^{1}$ Department of Materials Engineering, The University of Tokyo, 7-3-1 Hongo, Bunkyo-ku, Tokyo 113-8656, Japan \\ ${ }^{2}$ Research Center for Computational Design of Advanced Functional Materials, National Institute of Advanced Industrial Science \\ and Technology (AIST), 1-1-1 Umezono, Tsukuba, Ibaraki 305-8568, Japan \\ ${ }^{3}$ Institute for Solid State Physics, The University of Tokyo, 5-1-5 Kashiwa, Chiba 277-8581, Japan \\ ${ }^{4}$ Faculty of Science, Yamagata University, 1-4-12 Kojirakawa, Yamagata-shi, Yamagata 990-8560, Japan \\ ${ }^{5}$ Institute for Molecular Science, 38 Nishigo-Naka, Myodaiji, Okazaki, 444-8585, Japan
}

(Received 13 September 2018; revised manuscript received 23 October 2019; published 14 January 2020)

\begin{abstract}
We investigated $\mathrm{Li}$-ion distribution profiles at the interfaces between $\gamma-\mathrm{Li}_{3} \mathrm{PO}_{4}$ and metal electrodes using first-principles and one-dimensional continuum-model calculations. Within the allowed range of the chemical potential of $\mathrm{Li}$ in $\gamma-\mathrm{Li}_{3} \mathrm{PO}_{4},-6.11 \mathrm{eV} \leqslant \mu_{\mathrm{Li}} \leqslant-2.59 \mathrm{eV}$, which is estimated from the chemical potential diagram of Li, P, O-related chemical compounds, we predict upward band bending near $\mathrm{Au}(111)$ and $\mathrm{Ni}(111)$ interfaces. We found interstitial Li-ion accumulation for the larger $\mu_{\mathrm{Li}}$ values and its depth is ca. $3 \AA$ for $\mu_{\mathrm{Li}}=-2.59 \mathrm{eV}$. For the $\mathrm{Li}(100)$ interface with $\mu_{\mathrm{Li}}=-2.59 \mathrm{eV}$, we predict slight upward band bending and the formation of interstitial Li-ions. However, the downward band bending occurs for $\mu_{\mathrm{Li}}=-6.11 \mathrm{eV}$, where the accumulated charge carrier corresponds to the Li-ion vacancies. Finally, we suggest that the interstitial Li-ions accumulated within a few $\AA$ from the $\mathrm{Au}(111)$ interface and the Li-Au alloying play a central role in the switching of the novel memory device.
\end{abstract}

DOI: 10.1103/PhysRevMaterials.4.015402

\section{INTRODUCTION}

Li-ion acts as a mobile charge carrier in various liquids and solids, and understanding its behavior is of significant importance in the application to Li-ion batteries (LIBs), the demand of which increases rapidly. Among LIBs, all-solidstate type Li-ion batteries (ASSLIBs) have attracted much attention recently due to safety and high output voltage [1,2]. Although the low ionic conductivity of solid electrolytes has been considered as a drawback, sulfide-based materials were found to show high ionic conductivity of $\sim 10^{-2} \mathrm{~S} / \mathrm{cm}$ at room temperature $[3,4]$, which is comparable with that of liquid electrolytes. Thus, ASSLIBs are expected to be next generation secondary batteries.

Recently, the $\mathrm{Au} / \mathrm{Li}_{3} \mathrm{PO}_{4} / \mathrm{Li}$ stacked system, which has a similar geometry to ASSLIBs, has been found to exhibit two different internal voltage states, viz., high voltage state $\left(\sim 0.7 \mathrm{~V}\right.$ versus $\left.\mathrm{Li}^{+} / \mathrm{Li} ; \mathrm{HVS}\right)$ and low voltage state $(\sim 0.3$ $\mathrm{V}$ versus $\mathrm{Li}^{+} / \mathrm{Li}$; LVS) [5]. The transition from LVS to HVS (HVS to LVS) occurs by applying $2.0 \mathrm{~V}(0.2 \mathrm{~V})$ to the $\mathrm{Au}$ electrode. A new type of memory device may be realized by utilizing these switchable states. Experiments also verify that the switching of the two states requires a very low power consumption. The simple stacked structure is of advantage when applying to highly integrated systems, and the use of a fast ionic conductor electrolyte with low interface resistance enables high-speed operation. Therefore, we expect that this

\footnotetext{
*shimizu@cello.t.u-tokyo.ac.jp

†watanabe@cello.t.u-tokyo.ac.jp
}

stacked system may be promising as a novel memory device, and can contribute to further advances in the information intensive society.

The current-voltage characteristics obtained by the cyclic voltammetry measurement in the $\mathrm{Au} / \mathrm{Li}_{3} \mathrm{PO}_{4} / \mathrm{Li}$ stacked system show two remarkable peaks $[5,6]$. The peak at $0.2 \mathrm{~V}$ corresponds to the current from $\mathrm{Li}$ to $\mathrm{Au}$ electrodes, suggesting the Li-ion migration toward the Au electrode. However, the current flow from $\mathrm{Au}$ to $\mathrm{Li}$ electrodes around $0.5 \mathrm{~V}$ suggests the movement of the accumulated $\mathrm{Li}$-ion at the $\mathrm{Au}$ electrode toward the Li electrode. The current impedance measurement at the two voltage states reveals that the Nyquist plots of the HVS and LVS have one and two semicircles, respectively [5]. The one semicircle seen in both states originates from the resistance in $\mathrm{Li}_{3} \mathrm{PO}_{4}$. The origin of the second semicircle in the LVS is attributed to the $\mathrm{Au} / \mathrm{Li}_{3} \mathrm{PO}_{4}$ interface, which presumably arises from a thin $\mathrm{Li}-\mathrm{Au}$ alloy layer formation. These experimental results suggest that the two voltage states have different Li-ion distributions near the interface with the $\mathrm{Au}$ electrode. One may think that certain experimental techniques, e.g., scanning transmission electron microscopy (STEM) coupled with electron energy loss spectroscopy (EELS) [7], and high angle annular dark field (HAADF)STEM, can directly observe the interface structures $[8,9]$. However, due to the complexity of lithium related materials and insufficient sensitivities of such techniques for these materials, a consensus on the interface structures is yet to be reached. In this context, it is worth noting that the origin of interface resistance in these materials is still under discussion, though space charge layer (SCL) $[10,11]$ and solid electrolyte interphase (SEI) [12,13], etc., have been proposed as its 

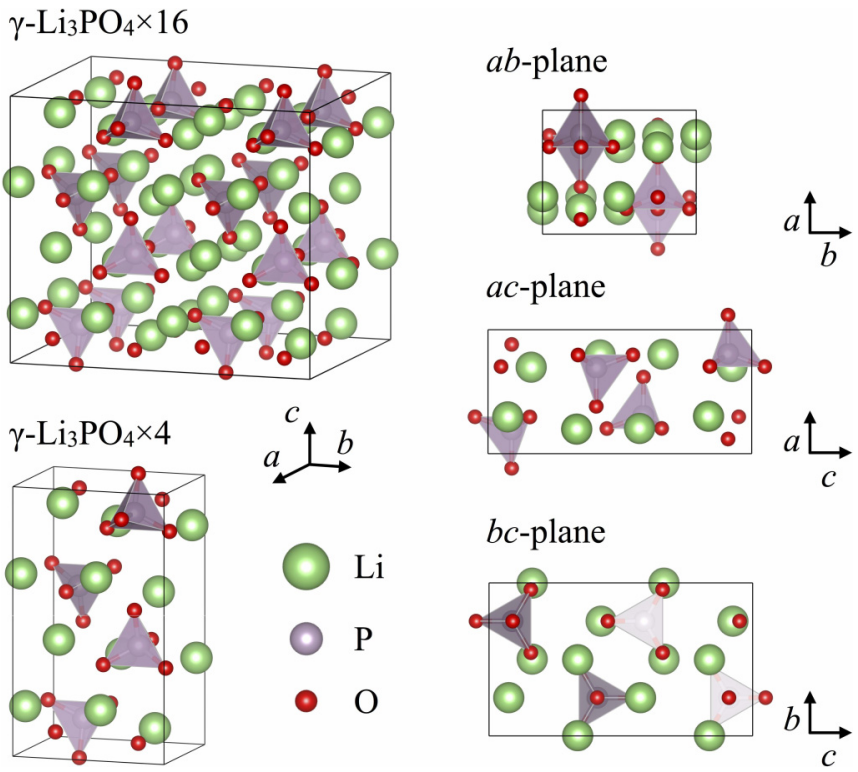

FIG. 1. Left: Optimized structure of bulk $\gamma-\mathrm{Li}_{3} \mathrm{PO}_{4}$ unit cell. Right: Top views of three planes, viz., $a b, a c$, and $b c$ planes. $\mathrm{PO}_{4}$ forms the tetrahedra. Structures are visualized using VESTA package [18].

possible origins. In this research, therefore, we conducted numerical simulations using first-principles calculations to elucidate the $\mathrm{Li}$-ion distribution at the interface of $\mathrm{Li}_{3} \mathrm{PO}_{4} /$ metal systems.

\section{METHODOLOGY}

\section{A. DFT calculations}

We first performed density functional theory (DFT)-based total energy calculations using Vienna ab initio Simulation Package (VASP) software $[14,15]$ to investigate the formation energy of Li defects, viz., vacancy and interstitial, in $\mathrm{Li}_{3} \mathrm{PO}_{4}$, and the valence band offset (VBO) values between $\mathrm{Li}_{3} \mathrm{PO}_{4}$ and metal surfaces. For all the calculations, we used the generalized gradient approximation (GGA) with PerdewBurke-Ernzerhof (PBE) functional [16], plane wave basis set (500 eV cutoff energy), and projector augmented wave (PAW) method [17]. We used the bulk $\gamma-\mathrm{Li}_{3} \mathrm{PO}_{4}(\times 16)$ for the defect calculations, which consists of $48 \mathrm{Li}, 16 \mathrm{P}$, and $64 \mathrm{O}$ atoms in the unit cell as shown in Fig. 1. To investigate Li-ion defects (charged defects), we varied the number of electrons $( \pm 1)$ by adding a jellium background charge to neutralize the unit cell.

The formation energy of defect species D with charge $q$ is defined as follows:

$$
G\left[\mathrm{D}^{q}\right]=E\left[\mathrm{D}^{q}\right]-E_{0}-n_{\mathrm{Li}} \mu_{\mathrm{Li}}+q \Delta E_{\mathrm{F}}+\Delta_{\text {corr }},
$$

where $E\left[\mathrm{D}^{q}\right]$ and $E_{0}$ correspond to the total energies of the defect $\mathrm{D}^{q}$ and the pristine systems, respectively. $n_{\mathrm{Li}}$ and $\mu_{\mathrm{Li}}$ are the number of Li defects per supercell and the chemical potential of $\mathrm{Li}$, respectively. $\Delta E_{\mathrm{F}}$ corresponds to the Fermi level measured from the VBM, which is equivalent to $\Delta E_{\mathrm{F}}(z)$ in Sec. II B. $\Delta_{\text {corr }}$ is the correction term for spurious interactions between the charged defect and the periodic images of the supercell $[19,20]$. It includes the effect of potential alignment of the defective system with respect to that of nondefective systems, as implemented in sxdefectalign software [21].

Then, we calculated the valence band maximum (VBM) of $\gamma-\mathrm{Li}_{3} \mathrm{PO}_{4}$ measured from the vacuum level using the slab approach. We examined three surface orientations, viz., $a b$, $a c$, and $b c$ planes (cf. right panel of Fig. 1), where each slab consists of three $\gamma-\mathrm{Li}_{3} \mathrm{PO}_{4}(\times 4)$ unit cells repeating the direction perpendicular to the surface plane. We used 23.3, 24.8 , and $23.8 \AA$ thick vacuum layers to separate $a b, a c$, and $b c$ plane slabs, respectively. Further details of the slab structures are described in Sec. S1 of the Supplemental Materials [22]. We applied the dipole correction along the direction perpendicular to the surface plane to eliminate the dipole interaction between the periodic cells for all slab calculations $[23,24]$. Note that the density of states (DOS) of the middle of the slab reproduce main features of DOS of the bulk $\gamma-\mathrm{Li}_{3} \mathrm{PO}_{4}$, such as the band widths and their relative energy positions. This may justify our choice for the slab thickness (for details, please see Fig. S2 in the Supplemental Material [22]).

Next, we calculated the work functions of $\mathrm{Au}, \mathrm{Ni}, \mathrm{Li}$, and $\mathrm{Li}-\mathrm{Au}$ alloys, viz., $\mathrm{LiAu}_{3}$ and $\mathrm{Li}_{3} \mathrm{Au}$, surfaces. Specifically, we examined the work functions of low index facets, (100), (110), and (111) for face-centered-cubic (FCC) $\mathrm{Au}, \mathrm{Ni}$, and $\mathrm{LiAu}_{3},(100)$ and (110) for body-centered-cubic (BCC) $\mathrm{Li}$, and (100) for rocksalt $\mathrm{Li}_{3} \mathrm{Au}$. Each slab consists of six atomic layers. We used $1 \times 1$ supercells, and the vacuum layers were more than $15 \AA$ for all cases. We calculated the work function values from the vacuum level measured from the Fermi level in the planar average of electrostatic potential. Brillouin zone integration was performed using the special $k$-point sampling technique of Monkhorst and Pack $(5 \times 5 \times 5$ and $5 \times 5 \times 1$ sampling meshes for the bulk and the slab systems, respectively) [25].

The optimized lattice constants of $\gamma-\mathrm{Li}_{3} \mathrm{PO}_{4}(\times 4)$ were calculated as $a: 5.00 \AA, b: 6.18 \AA$, and $c: 10.6 \AA$, which agree well with the experimental (previous DFT) values of $a$ : 4.92 (4.99) $\AA, b: 6.11$ (6.17) $\AA$, and $c: 10.5$ (10.58) $\AA$ [26,27]. The insulating electronic structure was confirmed with the band gap energy of $5.68 \mathrm{eV}$, although the value is much lower than the experimental one, $8.14 \mathrm{eV}$ [28], as often seen in GGA calculations. For metal surfaces, we used the optimized bulk lattice constants of $4.18 \AA, 3.52 \AA, 3.44 \AA, 4.07 \AA$, and $6.29 \AA$ for $\mathrm{Au}, \mathrm{Ni}, \mathrm{Li}, \mathrm{LiAu}_{3}$, and $\mathrm{Li}_{3} \mathrm{Au}$, respectively. We used $\mathrm{Au}$-termination for $\mathrm{LiAu}_{3}(100)$ and $\mathrm{Li}$-Au-termination for $\mathrm{LiAu}_{3}(110)$ and $\mathrm{Li}_{3} \mathrm{Au}(100)$ considering energetical stability.

\section{B. Continuum-model calculations}

We investigated the Li-ion distribution in $\gamma-\mathrm{Li}_{3} \mathrm{PO}_{4}$ solid electrolyte connected to metal electrode, using a combination of defect formation energy calculations from first principles and continuum-model calculations [29]. We adopted a one-dimensional (along the $z$ axis) continuum-model of $\gamma-\mathrm{Li}_{3} \mathrm{PO}_{4} /$ metal interfaces. A schematic description is shown in Fig. 2, where $\Delta E_{\mathrm{F}}(z)$ corresponds to the energy difference between the metal Fermi level, $E_{\mathrm{F}}$, and the electrolyte VBM, $V(z) . \Delta E_{\mathrm{F}}(z=0)$ corresponds to $\mathrm{VBO}, \phi_{\mathrm{VBO}}$. Here, we assumed the Schottky limit, where surface effects are not considered. That is, we assume that the VBO can be calculated 


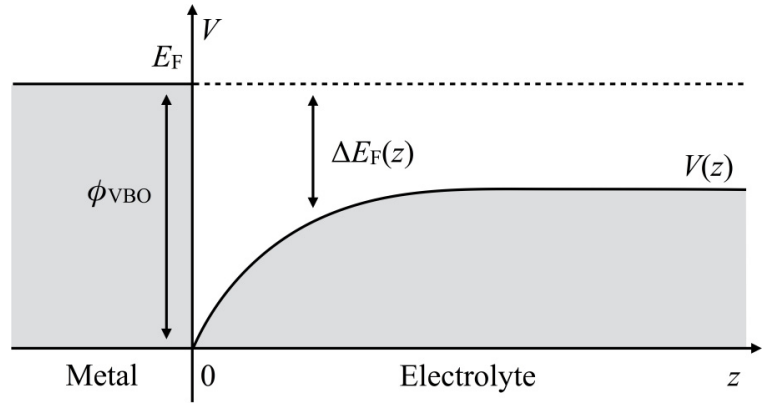

FIG. 2. A schematic description of one-dimensional continuummodel along $z$ axis. The band bending of electrolyte valence band is expected to be seen near the interface with metal, where the shaded areas represent the occupied energy states. $\phi_{\mathrm{VBO}}$ corresponds to the valence band offset. $\Delta E_{\mathrm{F}}(z)$ corresponds to the energy difference between the Fermi level of metal $\left(E_{\mathrm{F}}\right)$ and the valence band energy of electrolyte $V(z)$.

directly as the difference between the work function of the electrode and the valence band maximum of the electrolyte surface. We determined the electrostatic potential $V(z)$ based on Poisson's equation:

$$
\frac{\partial^{2} V(z)}{\partial z^{2}}=-\frac{\rho(z)}{\varepsilon_{0} \varepsilon_{\mathrm{r}}},
$$

where $\varepsilon_{0}$ corresponds to the permittivity of vacuum and $\varepsilon_{\mathrm{r}}$ corresponds to the dielectric constant of $\gamma-\mathrm{Li}_{3} \mathrm{PO}_{4}$. In these calculations, we considered four kinds of Li defects, viz., $\mathrm{V}_{\mathrm{Li}}^{\mathrm{x}}, \mathrm{V}_{\mathrm{Li}}^{\prime}, \mathrm{Li}_{\mathrm{i}}^{\mathrm{x}}$, and $\mathrm{Li}_{\mathrm{i}}$. $\mathrm{V}_{\mathrm{Li}}$ and $\mathrm{Li}_{\mathrm{i}}$ represent the $\mathrm{Li}$ vacancy and interstitial, respectively, and cross-mark (x), bullet (•), and prime (/) signs indicate neutral, positive, and negative charges, respectively, following Kröger-Vink notation [30]. We assumed that the charged defects contribute to the charge density, which is given by the following equation:

$$
\rho(z)=-\left[\mathrm{V}_{\mathrm{Li}}^{\prime}(z)\right]+\left[\mathrm{Li}_{\mathbf{i}}^{\bullet}(z)\right]-\left[e^{\prime}(z)\right]+\left[\mathrm{h}^{\bullet}(z)\right],
$$

where bracket represents the density of each defect species, and $\left[e^{\prime}(z)\right]$ and $\left[\mathrm{h}^{\bullet}(\mathrm{z})\right]$ correspond to the densities of electrons and holes, respectively. Each defect density takes the following form:

$$
\left[\mathrm{D}^{q}\right]=N \frac{\exp \left[\frac{-G\left[\mathrm{D}^{q}\right]}{k_{\mathrm{B}} T}\right]}{1+\sum_{q^{\prime}} \exp \left[\frac{-G\left[\mathrm{D}^{q^{\prime}}\right]}{k_{\mathrm{B}} T}\right]},
$$

where $N$ is the concentration of possible defect sites. $k_{\mathrm{B}}$ and $T$ correspond to the Boltzmann constant and temperature, respectively. The concentration of possible defect sites in $\gamma-\mathrm{Li}_{3} \mathrm{PO}_{4}$ corresponds to $N=3.66 \times 10^{28} \mathrm{~m}^{-3}$ (48 sites/unit cell). Note that although the number of interstitial sites are not uniquely determined, we assumed that it is the same as that of the vacancy sites. The carrier densities of electrons and holes were calculated using Fermi-Dirac distribution function. Since $G\left[\mathrm{D}^{q\left(q^{\prime}\right)}\right]$ depends on the local Fermi level position $\Delta E_{\mathrm{F}}(z)=\phi_{\mathrm{VBO}}-V(z)$ [cf. Eq. (1)], the charge density $\rho(z)$ turns out to be a function of $V(z)$. Thus, Eq. (2) is solved self-consistently to obtain the charge and potential profiles.
TABLE I. Calculated formation energies of the Li vacancy and interstitial in bulk $\gamma-\mathrm{Li}_{3} \mathrm{PO}_{4}(\times 16) . \mathrm{V}_{\mathrm{Li}}^{\mathrm{x}}\left(\mathrm{Li}_{\mathrm{i}}^{\mathrm{x}}\right)$ and $\mathrm{V}_{\mathrm{Li}}^{\prime}\left(\mathrm{Li}_{\mathrm{i}}{ }^{\bullet}\right)$ correspond to the Li vacancy (interstitial) of charge neutral and negatively (positively) charged systems, respectively. $\mu_{\mathrm{Li}}$ and $\Delta E_{\mathrm{F}}$ correspond to the chemical potential of $\mathrm{Li}$ and the Fermi level measured from the valence band maximum, respectively.

\begin{tabular}{lccc}
\hline \hline & Vacancy & Interstitial \\
\hline $\mathrm{V}_{\mathrm{Li}}^{\mathrm{x}}$ & $6.82 \mathrm{eV}+\mu_{\mathrm{Li}}$ & $\mathrm{Li}_{\mathrm{i}}^{\mathrm{x}}$ & $0.183 \mathrm{eV}-\mu_{\mathrm{Li}}$ \\
$\mathrm{V}_{\mathrm{Li}}^{\prime}$ & $7.75 \mathrm{eV}+\mu_{\mathrm{Li}}-\Delta E_{\mathrm{F}}$ & $\mathrm{Li}_{\mathrm{i}}^{-}$ & $-5.38 \mathrm{eV}-\mu_{\mathrm{Li}}+\Delta E_{\mathrm{F}}$ \\
\hline \hline
\end{tabular}

\section{RESULTS AND DISCUSSION}

\section{A. Li defects formation energy}

We first performed the Li defect formation energy calculations in bulk $\gamma-\mathrm{Li}_{3} \mathrm{PO}_{4}$ using DFT calculations. We took into account the Li vacancy and interstitial as Li defect species. In the vacancy case, we removed one of the Li atoms from the unit cell and performed structural optimization. However, we randomly added one Li atom in the unit cell and optimized the structure for the interstitial case. For both defects cases, we investigated 12 initial configurations, and the obtained minimum defect formation energies among them are listed in Table I (for the others, please see Fig. S3 in the Supplemental Material [22]). The values in the table correspond to the total energy differences among the defect configurations and the pristine one plus the correction term $\Delta_{\text {corr }} . \Delta_{\text {corr }}$ values are 0.399 and $0.414 \mathrm{eV}$ for $\mathrm{V}_{\mathrm{Li}}^{\prime}$ and $\mathrm{Li}_{\mathrm{i}}^{\bullet}$, respectively, where we used $\varepsilon_{\mathrm{r}}=5.6$ obtained from the experiment [31].

Inside the crystal, $\mathrm{Li}$ atoms donate one electron to the lattice to become $\left(\mathrm{Li}^{+}\right)$while $\mathrm{PO}_{4}$ tetrahedra receive the electrons and become $\mathrm{PO}_{4}^{3-}$. According to the Bader charge analysis [32,33], the charge state of the $\mathrm{Li}$ atoms correspond to $+0.853 \sim+0.899$. Figure 3 shows the DOS of pristine $\gamma-\mathrm{Li}_{3} \mathrm{PO}_{4}$, where the energy reference is set to the VBM. The electronic states around $-7 \mathrm{eV}$ consist of the $\mathrm{P} 3 s$-orbital and the $\mathrm{O} 2 s$ and $2 p$-orbitals. The $\mathrm{P} 3 p$-orbitals and the $\mathrm{O} 2 p$ orbitals constitute the electronic states between $\sim-5 \mathrm{eV}$ and $-4 \mathrm{eV}$. The electronic states between $-3 \mathrm{eV}$ to $-1 \mathrm{eV}$ originate from mainly the $\mathrm{P} 3 d$-orbitals and $\mathrm{O} 2 p$-orbitals, with a small contribution of $\mathrm{P} 3 p$-orbitals. Note that the contribution of $\mathrm{P} 3 d$-orbitals agrees with the previously reported molecular

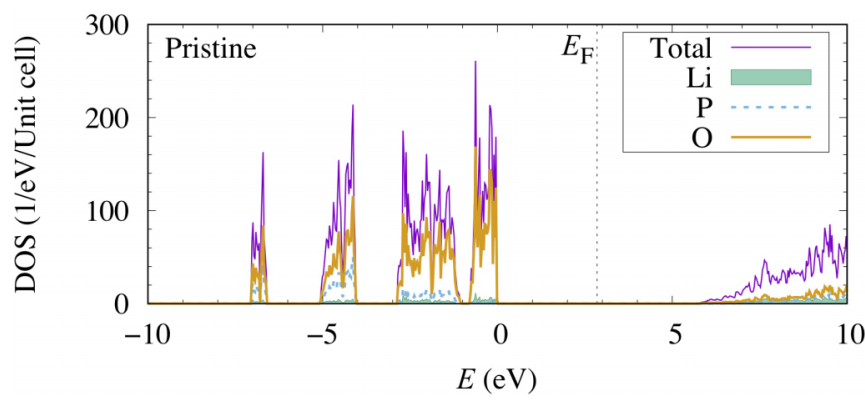

FIG. 3. Calculated density of states of pristine bulk $\gamma-\mathrm{Li}_{3} \mathrm{PO}_{4}$. The valence band maximum is taken as zero. The solid line corresponds to the total DOS, and the filled line, dotted line, and bold line correspond to the projected DOS to $\mathrm{Li}, \mathrm{P}$, and $\mathrm{O}$, respectively. 
(a)

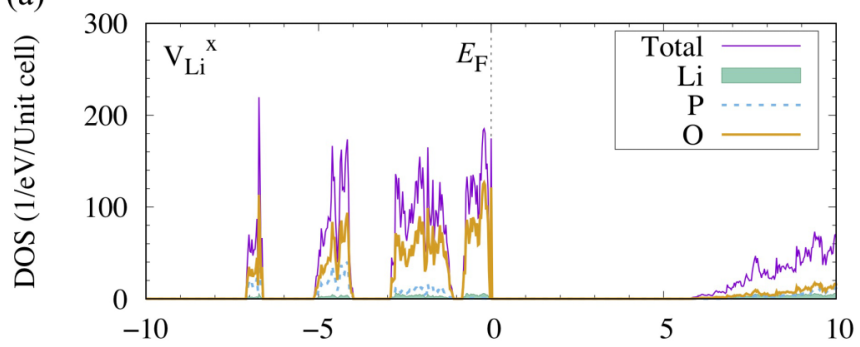

(b)

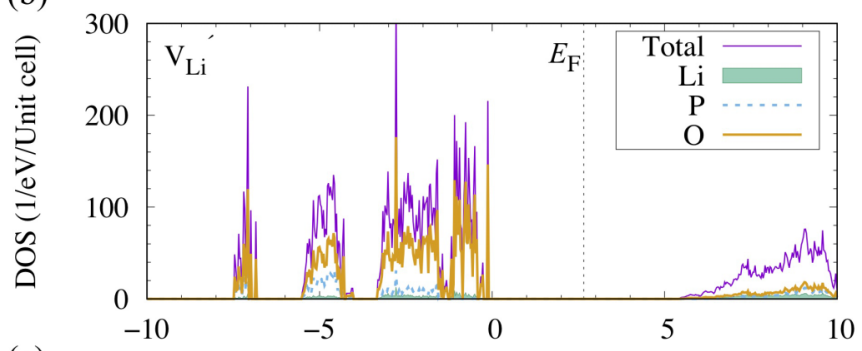

(c)

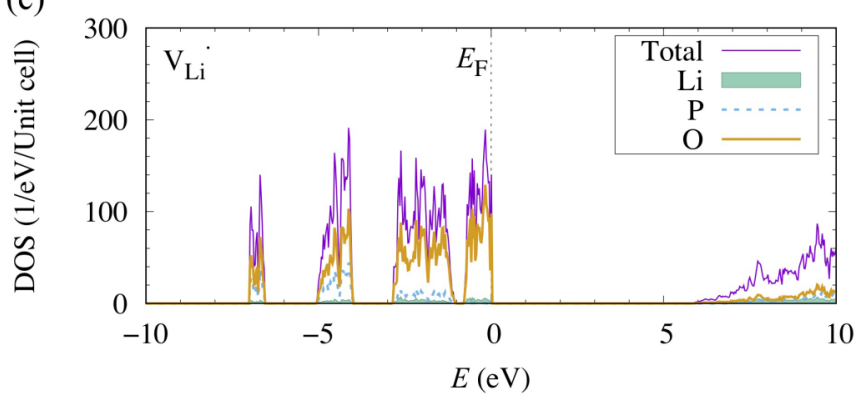

FIG. 4. Calculated density of states of bulk $\gamma-\mathrm{Li}_{3} \mathrm{PO}_{4}$ with $\mathrm{Li}$ vacancy; (a) $\mathrm{V}_{\mathrm{Li}}^{\mathrm{x}}$, (b) $\mathrm{V}_{\mathrm{Li}}^{\prime}$, and (c) $\mathrm{V}_{\mathrm{Li}}^{\bullet}$. The valence band maximum is taken as zero. The solid line corresponds to the total DOS, and the filled line, dotted line, and bold line correspond to the projected DOS to $\mathrm{Li}, \mathrm{P}$, and $\mathrm{O}$, respectively.

orbital calculations [34]. The electronic states near the VBM mainly consist of the nonbonding states of $\mathrm{O} 2 p$-orbitals, and the valence band is completely filled showing the insulating nature. The conduction band is separated by the band gap energy of $5.68 \mathrm{eV}$.

Figure 4 shows the DOS of $\gamma-\mathrm{Li}_{3} \mathrm{PO}_{4}$ with $\mathrm{Li}$ vacancies. In the case of $\mathrm{V}_{\mathrm{Li}}^{\mathrm{x}}$ [Fig. 4(a)], the valence band is not completely filled due to the lack of one electron in the $\mathrm{PO}_{4}$ tetrahedron. In the case of $\mathrm{V}_{\mathrm{Li}}^{\prime}$ [Fig. 4(b)], however, one additional electron fills the unoccupied electronic state restoring the insulating nature. The slight broadening of the valence band width is attributed to a lowering of $T_{d}$ symmetry of the $\mathrm{PO}_{4}$ tetrahedra. Lacking more electrons as in the case of $\mathrm{V}_{\mathrm{Li}}^{\cdot}$ [Fig. 4(c)] leads to more unoccupied states in the VBM.

The DOS of $\gamma-\mathrm{Li}_{3} \mathrm{PO}_{4}$ with $\mathrm{Li}$ interstitials are shown in Fig. 5. The interstitial $\mathrm{Li}$ atom releases one electron which stays in the conduction band in the case of $\mathrm{Li}_{\mathrm{i}}^{\mathrm{x}}$ [Fig. 5(a)]. More electrons stay in the conduction band in the case of $\mathrm{Li}_{\mathrm{i}}^{\prime}$ [Fig. 5(b)]. The VBM is fully occupied in the case of $\mathrm{Li}_{\mathrm{i}}^{-}$ [Fig. 5(c)], exhibiting the insulating nature. The band splitting in the charged defect cases is attributed to the symmetry lowering of the structures and the local electronic polarization in the crystal [35]. The shapes of DOS change slightly by the introduction of defects. Note that we set the number (a)

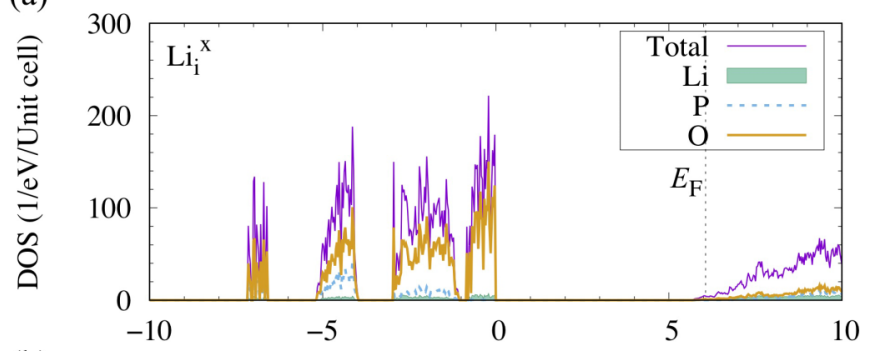

(b)

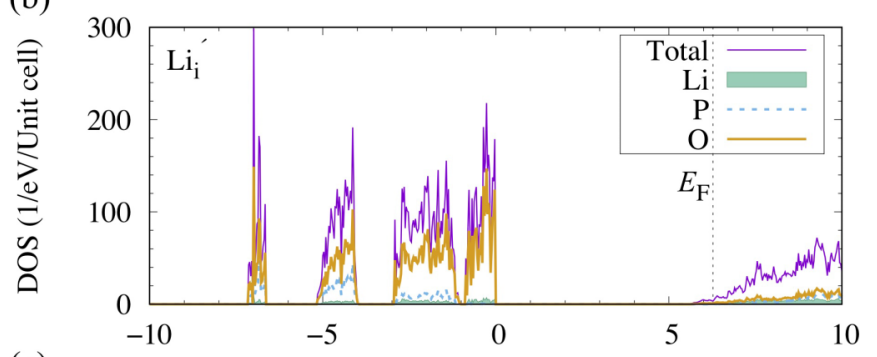

(c)

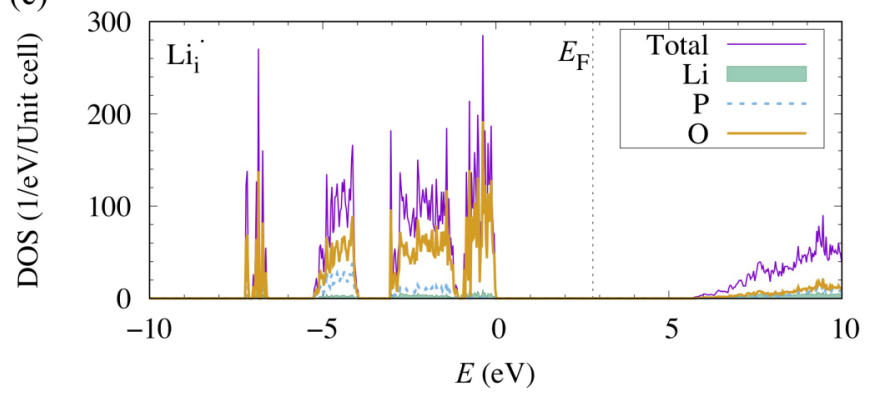

FIG. 5. Calculated density of states of bulk $\gamma-\mathrm{Li}_{3} \mathrm{PO}_{4}$ with interstitial $\mathrm{Li}$; (a) $\mathrm{Li}_{\mathrm{i}}^{\mathrm{x}}$, (b) $\mathrm{Li}_{\mathrm{i}}^{\prime}$, and (c) $\mathrm{Li}_{\mathrm{i}}^{\bullet}$. The valence band maximum is taken as zero. The solid line corresponds to the total DOS, and the filled line, dotted line, and bold line correspond to the projected DOS to $\mathrm{Li}, \mathrm{P}$, and $\mathrm{O}$, respectively.

of electrons and the background charges so as to formally simulate the six kinds of Li defects and that the formal charge state does not mean that the amount of the charge is localized at the defect site. In fact, in the cases of positively charged $\mathrm{Li}$ vacancy $\left(\mathrm{V}_{\mathrm{Li}}^{\bullet}\right)$ and negatively charged $\mathrm{Li}$ interstitial $\left(\mathrm{Li}_{\mathrm{i}}^{\prime}\right)$, the calculated charge density distributions show that the excess charges are delocalized over the supercell. This indicates that these defect species are unstable. Therefore, we excluded them from the possible defect species in the Li-ion distribution calculations in Sec. III D.

To confirm the validity of the Li defect formation energies using the GGA-PBE, where the band gap energy is underestimated, we performed hybrid functional calculations (HSE06) [36]. Note that since HSE06 calculations using $\gamma-\mathrm{Li}_{3} \mathrm{PO}_{4}(\times 16)$ are computationally intensive, we compared the results using $\gamma-\mathrm{Li}_{3} \mathrm{PO}_{4}(\times 4)$. We used the pristine and the most stable defect structures of $\gamma-\mathrm{Li}_{3} \mathrm{PO}_{4}(\times 4)$ obtained by the GGA-PBE calculations. The calculated band gap energy of the pristine structure corresponds to $7.55 \mathrm{eV}$, which is much closer to the experimental value [28]. The defect formation energies of $\mathrm{V}_{\mathrm{Li}}^{\mathrm{x}}, \mathrm{V}_{\mathrm{Li}}^{\prime}, \mathrm{Li}_{\mathrm{i}}^{\mathrm{x}}$, and $\mathrm{Li}_{\mathrm{i}}^{\bullet}$ using the HSE06 (GGAPBE) correspond to $7.71(6.89) \mathrm{eV}+\mu_{\mathrm{Li}}, 8.08(8.05) \mathrm{eV}+$ $\mu_{\mathrm{Li}}-\Delta E_{\mathrm{F}}, 1.40(0.997) \mathrm{eV}-\mu_{\mathrm{Li}}$, and $-5.33(-5.22) \mathrm{eV}-$ $\mu_{\mathrm{Li}}+\Delta E_{\mathrm{F}}$, respectively. The maximum difference of 
formation energies between the exchange-correlation functionals is $0.820 \mathrm{eV}\left(\mathrm{V}_{\mathrm{Li}}^{\mathrm{x}}\right)$. This is because the defect level of $\mathrm{V}_{\mathrm{Li}}^{\mathrm{x}}$ becomes relatively deeper in HSE06 compared with that of GGA-PBE. Although the difference is rather large, the formation energy of $\mathrm{V}_{\mathrm{Li}}^{\mathrm{x}}$ is the positive value regardless of $\Delta E_{\mathrm{F}}$ and $\mu_{\mathrm{Li}}$ and its density is small (cf. Sec. IIID2). Thus, this is expected to have negligible effects on the defect distribution and the switching mechanism which we will explain in Sec. III D.

The volume change of $\gamma-\mathrm{Li}_{3} \mathrm{PO}_{4}$ due to $\mathrm{Li}$ defects can be considered as a factor affecting the Li-ion distribution. Thus, we performed volume optimization calculations when the $\mathrm{Li}$ defects are introduced, using the bulk $\gamma-\mathrm{Li}_{3} \mathrm{PO}_{4}(\times 16)$ unit cell. In the vacancy case, we removed one of the $\mathrm{Li}$ atoms from the unit cell, and performed volume optimization. In the interstitial case, we randomly added one $\mathrm{Li}$ atom in the unit cell and optimized the volume. We found $0.197 \%, 1.22 \%$, $0.843 \%$, and $2.78 \%$ of volume expansions for $\mathrm{V}_{\mathrm{Li}}^{\mathrm{x}}, \mathrm{V}_{\mathrm{Li}}^{\prime}, \mathrm{Li}_{\mathrm{i}}^{\mathrm{x}}$, and $\mathrm{Li}_{\mathrm{i}}^{\prime}$, respectively. However, we found $0.755 \%$ and $1.03 \%$ volume shrinkage for $\mathrm{V}_{\mathrm{Li}}^{\bullet}$ and $\mathrm{Li}_{\mathrm{i}}^{\bullet}$, respectively. The obtained volume changes are rather small for all defect species, which suggests the unit cell size used in this study is sufficiently large. Thus, we used the defect formation energies without volume optimization for the following sections. For more details, please refer to Sec. S3 in the Supplemental Material [22].

\section{B. Li chemical potential}

To evaluate the Li defect formation energies, we need to consider the chemical potential value of $\mathrm{Li}$. The formation energy of $\gamma-\mathrm{Li}_{3} \mathrm{PO}_{4}$ is the sum of the chemical potentials of $\mathrm{Li}$, P, and $\mathrm{O}$, i.e., $E_{\text {form. }}\left(\gamma-\mathrm{Li}_{3} \mathrm{PO}_{4}\right)=3 \mu_{\mathrm{Li}}+\mu_{\mathrm{P}}+4 \mu_{\mathrm{O}}$. Depending on the environment (e.g., experimental conditions or source of $\mathrm{Li}$ ), each chemical potential value can vary in a certain energy range, which determines the stable chemical compound containing some or all of Li, P, and O [37]. Here, we determined the chemical potential energy range of $\mathrm{Li}$ where $\gamma-\mathrm{Li}_{3} \mathrm{PO}_{4}$ stably exists using the formation energy values of $\mathrm{Li}, \mathrm{P}$, and $\mathrm{O}$ related chemical compounds taken from Materials Project database [38]. Bulk BCC Li, bulk $\mathrm{P}$ in the monoclinic space group $P 2 / \mathrm{c}$, and an isolated $\mathrm{O}_{2}$ $\left(\frac{1}{2} \mathrm{O}_{2}\right)$ at $0 \mathrm{~K}$ were used to determine the formation energies. We considered $\mu_{\mathrm{Li}}=\mu_{\mathrm{Li}}^{0}+\Delta \mu_{\mathrm{Li}}$, where $\mu_{\mathrm{Li}}^{0}$ was taken as the total energy of bulk Li (per atom), which corresponds to $-1.90 \mathrm{eV}$ (this value depends on the zero reference for the total energy, which depends on how the pseudopotentials were generated; here, the value only has meaning as the reference for the chemical potential of Li). Figure 6 shows the chemical potential diagram for $\gamma-\mathrm{Li}_{3} \mathrm{PO}_{4}$ as functions of $\Delta \mu_{\mathrm{Li}}$ and $\Delta \mu_{\mathrm{O}}$. Note that the chemical potential of $\mathrm{P}\left(\mu_{\mathrm{P}}\right)$ is uniquely determined from the formation energy of $\gamma-\mathrm{Li}_{3} \mathrm{PO}_{4}$ when $\mu_{\mathrm{Li}}$ and $\mu_{\mathrm{O}}$ are specified.

In Fig. 6, there are numbered 17 lines, each of which corresponds to the chemical compound listed on the right side. The line indicates the phase boundary of the listed chemical compound and $\gamma-\mathrm{Li}_{3} \mathrm{PO}_{4}$. For instance, the line labeled 15 corresponds to the boundary of $\mathrm{Li}_{2} \mathrm{O}$ and $\gamma-\mathrm{Li}_{3} \mathrm{PO}_{4}$. When $\Delta \mu_{\mathrm{Li}}$ is smaller than the boundary, $\gamma-\mathrm{Li}_{3} \mathrm{PO}_{4}$ becomes stable. However, when $\Delta \mu_{\mathrm{Li}}$ is larger than the boundary, decomposi-

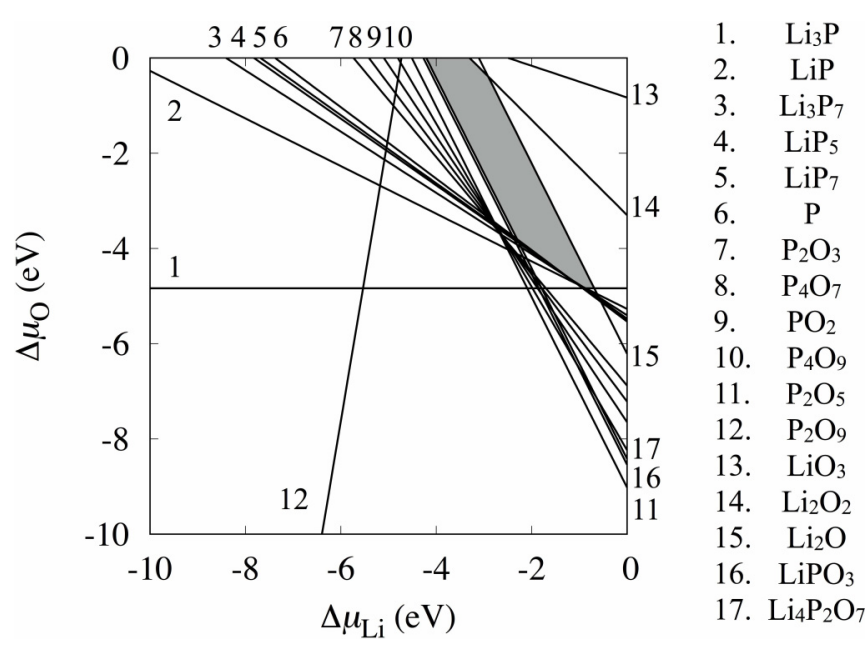

FIG. 6. Chemical potential diagram for $\gamma-\mathrm{Li}_{3} \mathrm{PO}_{4}$. The lines with numbers represent the stable phases (the chemical compounds listed on the right) in the corresponding chemical potential range. $\gamma-\mathrm{Li}_{3} \mathrm{PO}_{4}$ is stable with the chemical potentials in the shaded area.

tion of $\gamma-\mathrm{Li}_{3} \mathrm{PO}_{4}$ into $\mathrm{Li}_{2} \mathrm{O}$ occurs. In the area enclosed by all lines (shaded area), $\gamma-\mathrm{Li}_{3} \mathrm{PO}_{4}$ can stably exist. The resulting chemical potential range corresponds to $-6.11 \mathrm{eV} \leqslant \mu_{\mathrm{Li}} \leqslant$ $-2.59 \mathrm{eV}\left(-4.21 \mathrm{eV} \leqslant \Delta \mu_{\mathrm{Li}} \leqslant-0.690 \mathrm{eV}\right)$. In the following calculations, we will treat $\mu_{\mathrm{Li}}$ as a parameter in the above energy range.

\section{Valence band energy and work function}

We performed DFT calculations using the $\gamma-\mathrm{Li}_{3} \mathrm{PO}_{4}$ slab to obtain the VBM energy measured from the vacuum level. We used three surface structures shown in Fig. 1, viz., $a b, a c$, and $b c$ planes (please also refer to Fig. S1 in the Supplemental Material [22]). Table II shows the obtained VBM values for respective surface structures. The $a c$ plane shows the minimum VBM value because the Li fraction of this surface is the largest. The energy level becomes higher when the surface is positively charged. However, since the $b c$ plane has the $\mathrm{PO}_{4}$ protruded surface structure, it has the largest VBM value. The $a b$ plane takes the intermediate value.

Next, we calculated the surface energies to determine the most stable surface plane using the equation: $E_{\text {surf. }}=$ $\left(E_{\text {slab }}-3 E_{\text {bulk }}\right) / 2 A$. A corresponds to the surface area, and the coefficient 2 comes from the upper and lower surfaces in the slab. The coefficient 3 corresponds to the number of unit cells used in the slab model. The surface energy indicates the energy increase by cutting the surface from bulk. Thus, the smaller value of the surface energy means the stable surface.

TABLE II. Calculated valence band maximum values $\left(E_{\mathrm{VBM}}\right)$ and surface energies $\left(E_{\mathrm{s}}\right)$ of $\gamma-\mathrm{Li}_{3} \mathrm{PO}_{4} . a b, a c$, and $b c$ planes are taken into account (cf. Fig. 1).

\begin{tabular}{lcc}
\hline \hline & $E_{\mathrm{VBM}}(\mathrm{eV})$ & $E_{\mathrm{s}}\left(\mathrm{eV} / \AA^{2}\right)$ \\
\hline$a b$ plane & 5.89 & $3.24 \times 10^{-2}$ \\
$a c$ plane & 5.15 & $5.93 \times 10^{-2}$ \\
$b c$ plane & 6.46 & $6.24 \times 10^{-2}$ \\
\hline \hline
\end{tabular}


TABLE III. Calculated work function values $(\phi)$ of $\mathrm{Au}, \mathrm{Ni}, \mathrm{Li}$, $\mathrm{LiAu}_{3}$, and $\mathrm{Li}_{3} \mathrm{Au}$ surfaces. Low index facets, viz., (100), (110), and (111), are taken into account.

\begin{tabular}{lccccc}
\hline \hline & Facet & $\phi(\mathrm{eV})$ & & Facet & $\phi(\mathrm{eV})$ \\
\hline $\mathrm{Au}$ & $(100)$ & 4.99 & $\mathrm{Ni}$ & $(100)$ & 4.77 \\
& $(110)$ & 4.97 & $\mathrm{Ni}$ & $(110)$ & 4.51 \\
& $(111)$ & 5.15 & $\mathrm{Ni}$ & $(111)$ & 5.34 \\
$\mathrm{Li}$ & $(100)$ & 2.43 & $\mathrm{LiAu}_{3}$ & $(100)$ & 4.83 \\
& $(110)$ & 3.20 & $\mathrm{LiAu}_{3}$ & $(110)$ & 3.70 \\
$\mathrm{Li}_{3} \mathrm{Au}$ & $(100)$ & 3.22 & $\mathrm{LiAu}_{3}$ & $(111)$ & 4.73 \\
\hline \hline
\end{tabular}

The calculated surface energies shown in Table II suggest that the $a b$ plane is likely to be formed since it has the smallest surface energy value.

We also investigated the work function values of several metal surfaces. Here, we considered the $\mathrm{Au}, \mathrm{Ni}$, and $\mathrm{Li}$ surfaces used in the novel memory device as mentioned in the introduction. In addition, $\mathrm{Li}-\mathrm{Au}$ alloy surfaces, viz., $\mathrm{LiAu}_{3}$ and $\mathrm{Li}_{3} \mathrm{Au}$, were also taken into account. Note that $\mathrm{Au}$ has often been used as an electrode material in LIBs because of the storage capacity of $\mathrm{Li}$ by forming $\mathrm{Li}-\mathrm{Au}$ alloys $[6,39,40]$. Table III shows the calculated work function values. The results of $\mathrm{Au}, \mathrm{Ni}$, and $\mathrm{Li}$ surfaces agree well with the experimental values [41]. The work function of $\mathrm{Li}-\mathrm{Au}$ alloys decreases as Li percentage increases, i.e., $\phi_{\mathrm{Li}_{3} \mathrm{Au}}<\phi_{\mathrm{LiAu}_{3}}$.

\section{Li-ion distribution}

\section{Defect formation energy at interface}

The Li defect formation energies shown in Table I are plotted as a function of $\Delta E_{\mathrm{F}}$ with $\mu_{\mathrm{Li}}=-2.59 \mathrm{eV}$ in Fig. 7. The formation energies of $\mathrm{V}_{\mathrm{Li}}^{\mathrm{x}}$ and $\mathrm{Li}_{\mathrm{i}}^{\mathrm{x}}$ are constant regardless of
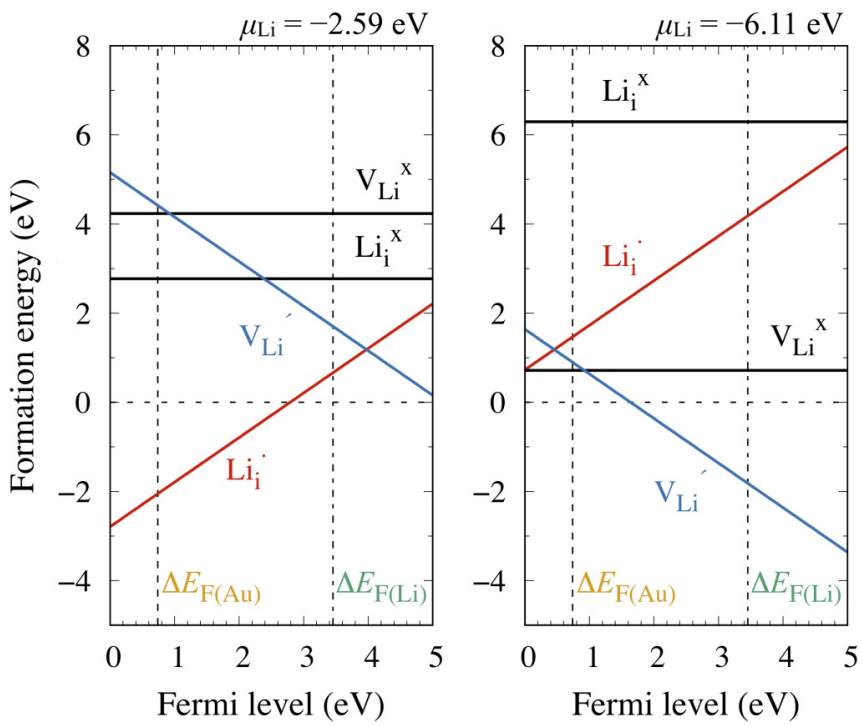

FIG. 7. Formation energies of the Li vacancy and interstitial of bulk $\gamma-\mathrm{Li}_{3} \mathrm{PO}_{4}$ as a function of Fermi level $\left(\Delta E_{\mathrm{F}}\right)$ measured from the valence band maximum. The chemical potential of $\mathrm{Li}$ corresponds to $\mu_{\mathrm{Li}}=-2.59 \mathrm{eV}$ (left) and $-6.11 \mathrm{eV}$ (right). The vertical lines show the valence band offset values of $\gamma-\mathrm{Li}_{3} \mathrm{PO}_{4}$ with $\mathrm{Au}(111)$ and Li(100).
$\Delta E_{\mathrm{F}}$. The formation energies of the charged defects increase or decrease with $\Delta E_{\mathrm{F}}$, depending on their charges. We then calculated the VBO values of metal-electrolyte interfaces by subtracting the work function of metal from the VBM of $\gamma-\mathrm{Li}_{3} \mathrm{PO}_{4}$.

At $\Delta E_{\mathrm{F}}=0.738 \mathrm{eV}$, which corresponds to $\mathrm{Au}(111)$, the formation energies of $\mathrm{Li}$ vacancies are so large that the formation of these defect species is unlikely at the interface. However, the interstitial $\mathrm{Li}$-ion $\left(\mathrm{Li}_{i}{ }^{*}\right)$ has a small formation energy of $-2.05 \mathrm{eV}$. This suggests that the interstitial Li-ions are likely to be formed. The formation energies of all defect species at $\Delta E_{\mathrm{F}}=3.45 \mathrm{eV}$, which corresponds to $\mathrm{Li}(100)$, have large values. Thus, the formation of defects is unlikely. Note that the previously reported $\mathrm{Li}_{\mathrm{i}}^{\bullet}$ formation energy at $E_{\mathrm{F}}=0 \mathrm{eV}$ corresponds to ca. $-3 \mathrm{eV}\left(\mu_{\mathrm{Li}}=-1.87 \mathrm{eV}\right)$ [42], which relatively agrees with the present study of $-2.79 \mathrm{eV}$ $\left(\mu_{\mathrm{Li}}=-2.59 \mathrm{eV}\right)$.

Figure 7 shows the $\mathrm{Li}$ defect formation energies as a function of $\Delta E_{\mathrm{F}}$ with $\mu_{\mathrm{Li}}=-6.11 \mathrm{eV}$. At the $\mathrm{Au}(111)$ Fermi level, the formation energy of interstitial $\mathrm{Li}$-ion $\left(\mathrm{Li}_{\mathrm{i}}^{\circ}\right)$ corresponds to $1.47 \mathrm{eV}$, which is much larger than that of $\mu_{\mathrm{Li}}=$ $-2.59 \mathrm{eV}$. Thus, interstitial Li-ions are unlikely to be formed in this case. However, the formation energy of Li-ion vacancy $\left(\mathrm{V}_{\mathrm{Li}}^{\prime}\right)$ at the $\mathrm{Li}(100)$ Fermi level shows a negative value of $-1.81 \mathrm{eV}$, and that of interstitial $\mathrm{Li}-\mathrm{ion}\left(\mathrm{Li}_{\mathrm{i}}^{\bullet}\right)$ becomes a large positive value. Therefore, the $\mathrm{Li}$-ion vacancy $\left(\mathrm{V}_{\mathrm{Li}}^{\prime}\right)$ is expected to act as a dominant defect species in this $\mu_{\mathrm{Li}}$ value.

\section{Continuum-model calculations}

To investigate the defect distributions and their depth from the interfaces, we performed the continuum-model calculations using the $\mathrm{Li}$ defect formation energies of bulk $\gamma-\mathrm{Li}_{3} \mathrm{PO}_{4}$ and the VBO values calculated assuming the Schottky limit as mentioned above. $\mu_{\mathrm{Li}}$ is treated as a parameter that can be modified experimentally by, e.g., application of bias. We used the $a b$ plane of $\gamma-\mathrm{Li}_{3} \mathrm{PO}_{4}$, the experimental values of the dielectric constant, $\varepsilon_{\mathrm{r}}=5.6$ [31], and the band gap energy, $E_{\mathrm{g}}=8.14 \mathrm{eV}$ [28]. The calculated electrostatic potential profiles from self-consistently solved Poisson's equation are shown in Fig. 8, where $\mu_{\mathrm{Li}}$ corresponds to $-2.59 \mathrm{eV}$ (ם), $-4.35 \mathrm{eV}(\bullet)$, and $-6.11 \mathrm{eV}(\bullet)$.

At the interface with $\mathrm{Au}(111)$, which has a relatively high work function, the electrostatic potentials show an upward band bending for $\mu_{\mathrm{Li}}=-2.59 \mathrm{eV}$ and $-4.35 \mathrm{eV}$, and a slight upward band bending for $\mu_{\mathrm{Li}}=-6.11 \mathrm{eV}$. The degree of bending increases as $\mu_{\mathrm{Li}}$ increases. The potential is flat in most of the region, which suggests that the interface affects only its neighborhood and the rest can be regarded as bulk. The calculated $\mathrm{Li}$ defect distribution profiles obtained from the charge density $\rho(z)$ are shown in Fig. 9, where the defect fraction equals one means that the defect sites are fully occupied. Near the interface with $\mathrm{Au}(111)$, the interstitial Li-ions $\left(\mathrm{Li}_{\mathrm{i}}^{\circ}\right.$ ) exist for $\mu_{\mathrm{Li}}=-2.59 \mathrm{eV}$ and $-4.35 \mathrm{eV}$. The depth of the defect-rich region reaches maximally ca. $4 \AA$ for $\mu_{\mathrm{Li}}=-2.59 \mathrm{eV}$, and the flat potential region has a negligible amount of defects. For the smaller $\mu_{\mathrm{Li}}$ values, the depth gradually decreases to ca. $2 \AA$ for $\mu_{\mathrm{Li}}=-4.35 \mathrm{eV}$. There are no interstitial Li-ions for $\mu_{\mathrm{Li}}=-6.11 \mathrm{eV}$, while holes $\left(\mathrm{h}^{\bullet}\right)$ and $\mathrm{Li}$ vacancies $\left(\mathrm{V}_{\mathrm{Li}}^{\mathrm{x}}\right.$ and $\left.\mathrm{V}_{\mathrm{Li}}^{\prime}\right)$ slightly exist as shown 

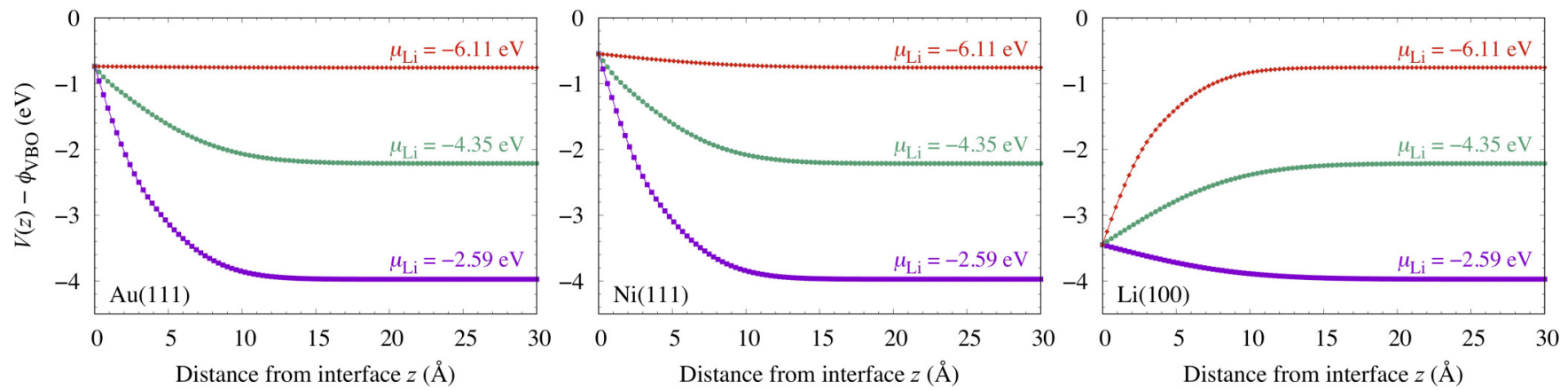

FIG. 8. Calculated electrostatic potential profiles of $\gamma-\mathrm{Li}_{3} \mathrm{PO}_{4}$ as a function of the distance from the interface $z$, with $\mathrm{Au}(111), \mathrm{Ni}(111)$, and $\mathrm{Li}(100)$. The reference of the electrostatic potential corresponds to the Fermi level of metal surfaces. The chemical potential of Li corresponds to $\mu_{\mathrm{Li}}=-2.59 \mathrm{eV}(\boldsymbol{\square}),-4.35 \mathrm{eV}(\bullet)$, and $-6.11 \mathrm{eV}(\diamond)$.

in the inset of Fig. 9. In this way, the positive charge carrier accumulates at the upward band bending region, and its depth corresponds to the strength of the potential screening. The dominant defect species, i.e., interstitial $\mathrm{Li}$-ions $\left(\mathrm{Li}_{\mathrm{i}}^{\bullet}\right)$, match with Fig. 7.

The calculated potential profile of $\mathrm{Ni}(111)$ interface case resembles that of $\mathrm{Au}(111)$ because of the similar work function value. That is, the electrostatic potential profiles show an upward band bending, and the positive charge carrier corresponds to interstitial Li-ions for $\mu_{\mathrm{Li}}=-2.59 \mathrm{eV}$ and $-4.35 \mathrm{eV}$, and holes for $\mu_{\mathrm{Li}}=-6.11 \mathrm{eV}$.

The VBO of $\mathrm{Li}(100)$ is larger than the above two cases due to its small work function value. The electrostatic potential profile with $\mu_{\mathrm{Li}}=-2.59 \mathrm{eV}$ shown in Fig. 8 indicates a slight upward band bending. In this case, the interstitial Li-ions $\left(\mathrm{Li}_{\mathrm{i}}^{\bullet}\right)$ slightly accumulate near the interface as seen in the
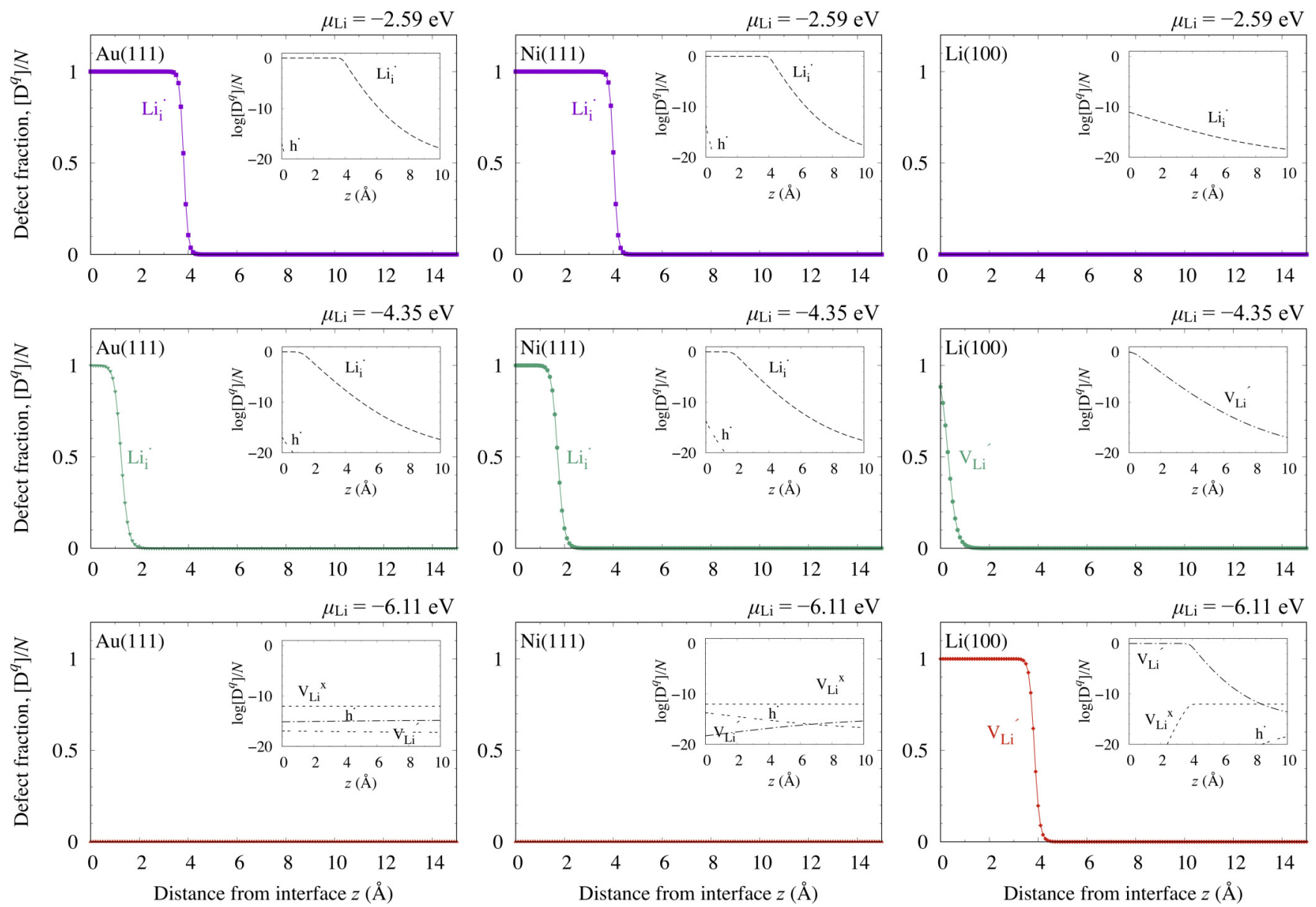

FIG. 9. Calculated Li defect fraction profiles of $\gamma-\mathrm{Li}_{3} \mathrm{PO}_{4}$ as a function of the distance from the interface $z$, with $\mathrm{Au}(111), \mathrm{Ni}(111)$, and $\mathrm{Li}(100)$. The chemical potential of $\mathrm{Li}$ corresponds to $\mu_{\mathrm{Li}}=-2.59 \mathrm{eV}(\boldsymbol{\square}),-4.35 \mathrm{eV}(\bullet)$, and $-6.11 \mathrm{eV}(\boldsymbol{\vee})$. The types of $\mathrm{Li}$ defects are indicated in the figures. The insets show the defect fraction profiles using logarithmic plots, with an indicated $\mu_{\mathrm{Li}}$. 
inset of Fig. 9. This can be explained by a relatively small formation energy of $0.659 \mathrm{eV}$ from Fig. 7. The formation energies of $\mathrm{Li}$ vacancy and interstitial pair at $\mathrm{Li}$ metal and $\mathrm{Li}_{3} \mathrm{PO}_{4}$, respectively, were reported as the positive values of $0.82 \mathrm{eV} \sim 2.1 \mathrm{eV}$, using DFT calculations with atomistic models of $\mathrm{Li}(100) / \beta$ - and $\gamma-\mathrm{Li}_{3} \mathrm{PO}_{4}$ interfaces $[42,43]$. Our results, which show the negligible amount of Li defects at the interface with $\mathrm{Li}(100)$, are consistent with the literatures. For smaller $\mu_{\mathrm{Li}}$ values, however, the electrostatic potential profiles show a downward band bending. The accumulation of Li-ion vacancies $\left(\mathrm{V}_{\mathrm{Li}}^{\prime}\right)$ gradually increases and its depth reaches ca. $4 \AA$ for $\mu_{\mathrm{Li}}=-6.11 \mathrm{eV}$.

The depth of the accumulated interstitial Li-ions near the interface depends on the assumed number of defect sites $N$. (Here, the number of defect sites means the upper limit of the defect density in a structural unit. This number for Li defects may be different from the number of Li atoms in the structural unit, especially for the interstitial case.) The electrostatic potential decreases slowly and steeply from the interface for the smaller and larger $N$, respectively. Correspondingly, the depth of the defect-rich region changes. The relevant defect species is still identical. Please refer to Sec. S4 of the Supplemental Material [22] for more details.

At the flat potential region, $\Delta E_{\mathrm{F}}(z>15 \AA)=\phi_{\mathrm{VBO}}-$ $V(z>15 \AA)=3.97 \mathrm{eV}$ and $0.757 \mathrm{eV}$ for $\mu_{\mathrm{Li}}=-2.59 \mathrm{eV}$ and $-6.11 \mathrm{eV}$, respectively, all defect species have positive formation energies according to Fig. 7. Thus, there is only a negligible amount of defects in the bulk region. The relatively low ionic conductivity of Li-ion in pure $\mathrm{Li}_{3} \mathrm{PO}_{4}$ is attributed to the high enthalpy of its defect formation energy $[44,45]$. The introduction of the defect into $\mathrm{Li}_{3} \mathrm{PO}_{4}$ through the combination of other materials, e.g., the composite with porous $\mathrm{Al}_{2} \mathrm{O}_{3}$ [44] and the solid solution with $\mathrm{Li}_{4} \mathrm{SiO}_{4}$ [45], largely enhances the ionic conductivity. The results obtained here are consistent with the experiments.

As mentioned in the introduction, the novel memory device using the $\mathrm{Au} / \mathrm{Li}_{3} \mathrm{PO}_{4} / \mathrm{Li}$ stacked system contains a $\mathrm{Li}$ source (Li metal electrode). This leads to the Li-rich condition, i.e., $\mu_{\mathrm{Li}}=-2.59 \mathrm{eV}$, which corresponds to the upper bound of $\mu_{\mathrm{Li}}$ in $\gamma-\mathrm{Li}_{3} \mathrm{PO}_{4}$. Thus, the $\mathrm{Li}$-ion vacancies possibly formed at the $\mathrm{Li}(100)$ interface in the fabrication process will disappear after a while, and the small amount of interstitial Li-ions will accumulate. Meanwhile, the interstitial Li-ions will increase near the $\mathrm{Au}(111)$ interface. Since Li-Au is a solid solution system [46], the Li-Au alloy formation is expected at the LVS. Using the work function values of Li-Au alloy surfaces, we calculated the electrostatic potentials and the defect fractions at these interfaces with $\mu_{\mathrm{Li}}=-2.59 \mathrm{eV}$ as shown in Fig. 10. The potential profiles show an upward bending, where the interstitial $\mathrm{Li}$-ions $\left(\mathrm{Li}_{\mathrm{i}}^{\bullet}\right)$ accumulate near the interfaces. However, the amount of interstitial Li-ions decreases for the alloy cases. This suggests that the Au surface is partially alloyed with the interstitial $\mathrm{Li}$-ions to form $\mathrm{LiAu}_{3}$ surface. Further alloying proceeds by the low voltage application to form $\mathrm{Li}_{3} \mathrm{Au}$ or more $\mathrm{Li}$-rich $\mathrm{Li}$-Au alloy surfaces. However, the high voltage application dissolves the Li-ions in the alloy, which stay near the interface as the interstitial Li-ions.

In this way, we can explain the switching of the memory device by the presence of interstitial Li-ions within a few $\AA$ from the $\mathrm{Au}(111)$ interface and the alloying of $\mathrm{Au}$ with
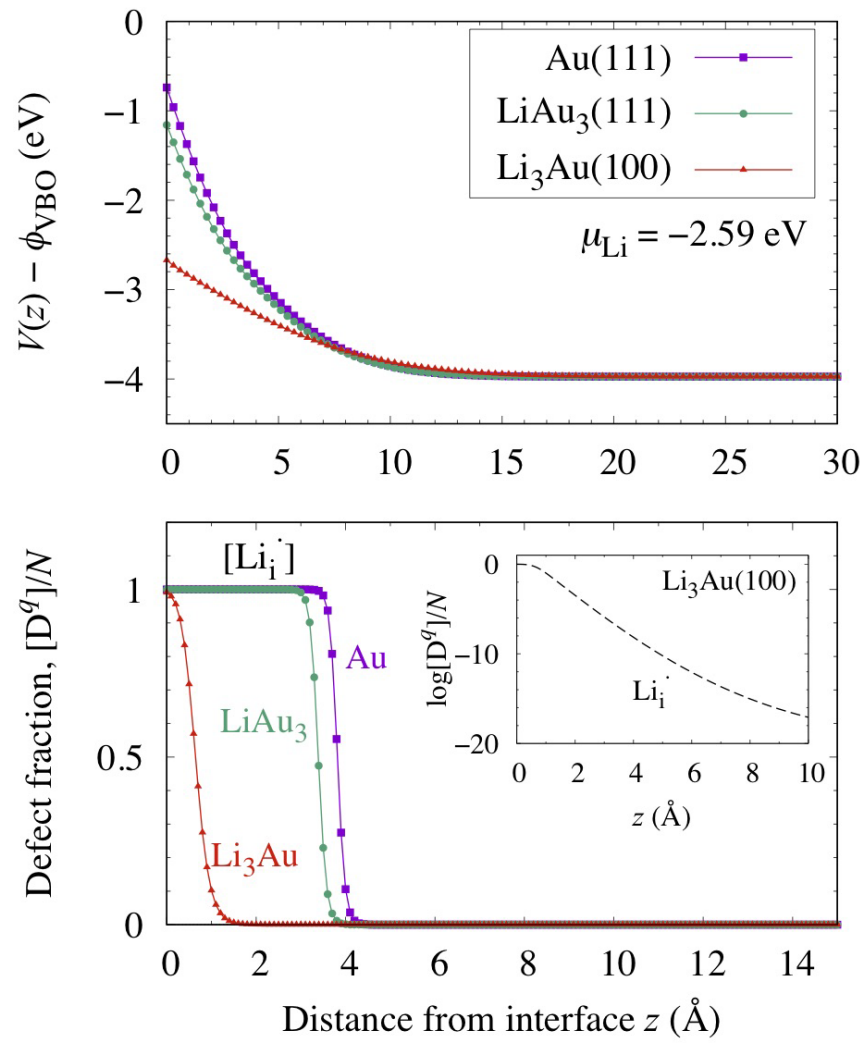

FIG. 10. Calculated electrostatic potential and $\left[\mathrm{Li}_{\mathrm{i}}^{\bullet}\right]$ defect fraction profiles of $\gamma-\mathrm{Li}_{3} \mathrm{PO}_{4}$ as a function of the distance from the interface $z$, with $\mathrm{Au}(111)(\boldsymbol{\square}), \mathrm{LiAu}_{3}(111)(\bullet)$, and $\mathrm{Li}_{3} \mathrm{Au}(100)(\boldsymbol{\Delta})$. The reference of the electrostatic potential corresponds to the Fermi level of metal surfaces. The chemical potential of Li corresponds to $\mu_{\mathrm{Li}}=-2.59 \mathrm{eV}$.

Li-ions. In the case of $\mathrm{Ni}$, however, the low-voltage application may cause the $\mathrm{Li}$ plating or the $\mathrm{Li}$ penetration into the grain boundaries, since Ni does not form an alloy with $\mathrm{Li}$.

The defect fraction profiles in Fig. 9 show the quite high $\mathrm{Li}$ density in $\gamma-\mathrm{Li}_{3} \mathrm{PO}_{4}$ near the interface with $\mathrm{Au}(111)$ and $\mathrm{Ni}(111)$. This also suggests the possibility of $\gamma-\mathrm{Li}_{3} \mathrm{PO}_{4}$ decomposition due to the thermal instability or the elongation of the defect-rich region to decrease the Li density. Side reactions may result in lower device performance.

In the continuum-model calculations, we assumed the Schottky limit, as mentioned in the Introduction. Since materials with large band gap energies are likely to be in this limit [47], we consider that our assumption is valid to some extent because of the large band gap energy of $\gamma-\mathrm{Li}_{3} \mathrm{PO}_{4}$. However, the interface of $\mathrm{Li}$-ion conducting solid electrolytes often loses its sharpness, and it is expected to form various impurity states at the interface. Thus, the model used here roughly approximates the actual interface structure. Nevertheless, previous calculations proved that in the case of oxygen vacancy using the atomistic model of $\mathrm{Ni} / \mathrm{ZrO}_{2}(111)$, the defect formation energies near the interface match well with the ones estimated using the bulk calculations assuming $\Delta E_{\mathrm{F}}$ as the VBO values [48]. The deviation of defect formation energies is within ca. $1 \mathrm{eV}$, which is due to the effects of interface and defect density. This supports the validity of the present work. Note that the structural relaxation may affect 
the formation of defect at the interface with Li electrode, e.g., the interstitial $\mathrm{Li}$ atom compensates the vacancy position in the $\mathrm{Li}(100) / \gamma-\mathrm{Li}_{3} \mathrm{PO}_{4}$ model [42].

\section{Origin of interface resistance}

In the experiment, the LVS and HVS appear after the 0.2 and $2.0 \mathrm{~V}$ voltage applications, respectively, where the only LVS shows the interface resistance [5]. When the $2.0 \mathrm{~V}$ is applied, Li-ions transfer inside the electrolyte from $\mathrm{Au}$ electrode side toward Li electrode side, which results in the $\mathrm{Li}$-poor condition near the $\mathrm{Au}$ electrode. However, Li-ions transfer in the opposite way at the $0.2 \mathrm{~V}$ application, which causes the Li-rich condition near the Au electrode. Within the allowed range of chemical potential of Li (cf. Fig. 6), $\mu_{\mathrm{Li}}=-2.59 \mathrm{eV}$ can be considered as the Li-rich condition. The defect distribution profile shows that the interstitial Liions are accumulated near the $\mathrm{Au}(111)$ at $\mu_{\mathrm{Li}}=-2.59 \mathrm{eV}$ (cf. Fig. 9), and presumably these can partially alloy the $\mathrm{Au}(111)$ surface. In the Li-poor condition, where $\mu_{\mathrm{Li}}$ may be close to the lower limit $(-6.11 \mathrm{eV})$, almost no defects accumulate near the interface. Therefore, we ascribe the origin of the interface resistance in the LVS to the accumulated interstitial Li-ions near the $\mathrm{Au}(111)$ interface and the partially alloyed $\mathrm{Au}$ surface. The microscopic mechanisms describing these interfaces are beyond the scope of the present work and we leave these considerations in the future studies.

Experiments also reported that the novel memory devices with $4 \mathrm{~mm}^{2}$ surface area consumes ca. $3 \times 10^{-5} \mathrm{C}$ during the voltage switching (LVS to HVS, vice versa) [5]. Using the experimental surface area and ca. $4 \AA$ depth of the accumulated interstitial Li-ions from the interface, we estimated the amount of charges necessary for the switching to be ca. $0.9 \times 10^{-5} \mathrm{C}$. We consider this to be a rather good match with the experiment because our numerical value of charge was obtained using several approximations such as the fixed dielectric constant and the absence of consideration of the defect-defect interaction. Besides, the relatively large sample size in the experiment may consume extra charges for various reasons, which are not directly related to the switching process. This value can be further improved if we employ realistic conditions, which is beyond the scope of our study.

\section{CONCLUSION}

We investigated the $\mathrm{Li}$-ion distribution in $\gamma-\mathrm{Li}_{3} \mathrm{PO}_{4}$ with metal interfaces using first-principles and one-dimensional continuum-model calculations. Using the formation energies of $\mathrm{Li}$ defects, $\mathrm{Li}$ vacancies and interstitials in bulk $\gamma-\mathrm{Li}_{3} \mathrm{PO}_{4}$ obtained by DFT calculations, we determined the electrostatic potential and the charge density by solving the Poisson's equation self-consistently. The range of the chemical potential of $\mathrm{Li}$ was evaluated from the chemical potential diagram of $\gamma-\mathrm{Li}_{3} \mathrm{PO}_{4}$ as $-6.11 \mathrm{eV} \leqslant \mu_{\mathrm{Li}} \leqslant-2.59 \mathrm{eV}$. We found upward band bending and the interstitial Li-ions accumulation near the $\mathrm{Au}(111)$ and $\mathrm{Ni}(111)$ interfaces for the larger $\mu_{\mathrm{Li}}$ values. The depth of the defect-rich region reaches maximally ca. $4 \AA$ for $\mu_{\mathrm{Li}}=-2.59 \mathrm{eV}$, and it gradually decreases for the smaller $\mu_{\mathrm{Li}}$ values. For the $\operatorname{Li}(100)$ interface with $\mu_{\mathrm{Li}}=$ $-2.59 \mathrm{eV}$, we found slight upward band bending and the formation of interstitial Li-ions. However, for $\mu_{\mathrm{Li}}=-6.11 \mathrm{eV}$, downward band bending occurs, and the Li-ion vacancies are accumulated at the interface. Finally, we suggest that the presence of interstitial $\mathrm{Li}$-ions and the $\mathrm{Li}-\mathrm{Au}$ alloying play a central role in the switching of the novel memory device.

In this research, we consider ideal interfaces and ignore various factors which may affect the Li-ion distribution, e.g., volume changes depending on the defect concentration and structural relaxation at the interfaces. For further investigation, we need to treat more realistic or complicated interface systems from first principles, which exceed current supercomputer capability. This could be resolved by advanced calculation methods having both reliability and computational efficiency such as interatomic potentials constructed using neural networks [49]. Nevertheless, the insights obtained in this paper must be helpful in advancing not only the novel memory device but also other ion conducting devices such as ASSLIBs, solid oxide fuel cells, and resistive random access memories.

\section{ACKNOWLEDGMENTS}

We thank Prof. T. Hitosugi, Prof. Susumu Shiraki, Dr. Ryota Shimizu, Dr. Issei Sugiyama, Dr. Kazunori Nishio, and Dr. Elvis F. Arguelles for fruitful discussions. This work was supported by JST CREST Program "Novel electronic devices based on nanospaces near interfaces" and JSPS KAKENHI Grants No. 26107514 and No. 15H03561. Some of the calculations presented here were done using the computer facilities at ISSP Supercomputer center and Information technology center, University of Tokyo, and Institute for Materials Research, Tohoku University (MASAMUNE-IMR). S.K. is also supported by JSPS KAKENHI Grant No. 15K20953.
[1] K. Takada, Acta Mater. 61, 759 (2013).

[2] M. Haruta, S. Shiraki, T. Suzuki, A. Kumatani, T. Ohsawa, Y. Takagi, R. Shimizu, and T. Hitosugi, Nano Lett. 15, 1498 (2015).

[3] N. Kamaya, H. Homma, Y. Yamakawa, M. Hirayama, R. Kanno, M. Yonemura, T. Kamiyama, Y. Kato, S. Hama, K. Kawamoto, and A. Mitsui, Nat. Mater. 10, 682 (2011).

[4] Y. Seino, T. Ota, K. Takada, A. Hayashi, and M. Tatsumisago, Energy Environ. Sci. 7, 627 (2014).

[5] I. Sugiyama, R. Shimizu, T. Suzuki, K. Yamamoto, H. Kawasoko, S. Shiraki, and T. Hitosugi, APL Mater. 5, 046105 (2017).
[6] H. Tavassol, M. K. Y. Chan, M. G. Catarello, J. Greeley, D. G. Cahill, and A. A. Gewirth, J. Electrochem. Soc. 160, A888 (2013).

[7] Z. Wang, D. Santhanagopalan, W. Zhang, F. Wang, H. L. Xin, K. He, J. Li, N. Dudney, and Y. S. Meng, Nano Lett. 16, 3760 (2016).

[8] X. Hu, S. Kobayashi, Y. H. Ikuhara, C. A. J. Fisher, Y. Fujiwara, K. Hoshikawa, H. Moriwake, K. Kohama, H. Iba, and Y. Ikuhara, Acta Mater. 123, 167 (2017).

[9] R. Huang, T. Hitosugi, S. D. Findlay, C. A. J. Fisher, Y. H. Ikuhara, H. Moriwake, H. Oki, and Y. Ikuhara, Appl. Phys. Lett. 98, 051913 (2011). 
[10] N. Ohta, K. Takada, L. Zhang, R. Ma, M. Osada, and T. Sasaki, Adv. Mater. 18, 2226 (2006).

[11] J. Haruyama, K. Sodeyama, L. Han, K. Takada, and Y. Tateyama, Chem. Mater. 26, 4248 (2014).

[12] D. Aurbach, J. Power Sources 89, 206 (2000).

[13] P. Verma, P. Maire, and P. Novák, Electrochim. Acta 55, 6332 (2010).

[14] G. Kresse and J. Furthmüller, Comput. Mater. Sci. 6, 15 (1996).

[15] G. Kresse and J. Furthmüller, Phys. Rev. B 54, 11169 (1996).

[16] J. P. Perdew, K. Burke, and M. Ernzerhof, Phys. Rev. Lett. 77, 3865 (1996)

[17] P. E. Blöchl, Phys. Rev. B 50, 17953 (1994).

[18] K. Momma and F. Izumi, J. Appl. Cryst. 44, 1272 (2011).

[19] C. Freysoldt, J. Neugebauer, and C. G. Van de Walle, Phys. Rev. Lett. 102, 016402 (2009).

[20] C. Freysoldt, J. Neugebauer, and C. G. Van de Walle, Phys. Stat. Sol. B 248, 1067 (2011).

[21] https://sxrepo.mpie.de/.

[22] See Supplemental Material at http://link.aps.org/supplemental/ 10.1103/PhysRevMaterials.4.015402 for additional calculations and analyses of slab structures, $\mathrm{Li}$ defects, and $\mathrm{Li}$-ion distributions at $\gamma-\mathrm{Li}_{3} \mathrm{PO}_{4}$.

[23] G. Makov and M. C. Payne, Phys. Rev. B 51, 4014 (1995).

[24] J. Neugebauer and M. Scheffler, Phys. Rev. B 46, 16067 (1992).

[25] H. J. Monkhorst and J. D. Pack, Phys. Rev. B 13, 5188 (1976).

[26] B. Wang, B. C. Chakoumakos, B. C. Sales, B. S. Kwak, and J. B. Bates, J. Solid State Chem. 115, 313 (1995).

[27] Y. A. Du and N. A. W. Holzwarth, Phys. Rev. B 76, 174302 (2007).

[28] F. Harbach and F. Fischer, Phys. Stat. Sol. B 66, 237 (1974).

[29] S. Kasamatsu, T. Tada, and S. Watanabe, Solid State Ionics 183, 20 (2011).
[30] F. A. Kröger and H. J. Vink, in Solid State Physics, edited by F. Seitz and D. Turnbull (Academic Press, New York, 1956), Vol. 3, p. 307.

[31] A. Gassmann, C. Melzer, and H. von Seggern, Synth. Met. 161, 2575 (2012).

[32] R. F. W. Bader, Atoms in Molecules: A Quantum Theory, (Oxford University Press, Oxford, 1990).

[33] G. Henkelman, A. Arnaldsson, and H. Jónsson, Comput. Mater. Sci. 36, 354 (2006).

[34] J. A. Connor, I. H. Hillier, and V. R. Saunders, Molec. Phys. 23, 81 (1972).

[35] M. Heggie and R. Jones, J. Phys. C: Solid State Phys. 14, 4603 (1981).

[36] A. V. Kurkau, O. A. Vydrov, A. F. Izmaylov, and G. E. Scuseria, J. Chem. Phys. 125, 224106 (2006).

[37] K. Hoang and M. Johannes, Chem. Mater. 23, 3003 (2011).

[38] http://www.materialsproject.org.

[39] Z. Zeng, W.-I. Liang, Y.-H. Chu, and H. Zheng, Faraday Discuss. 176, 95 (2014)

[40] P. Bach, I. Valencia-Jaime, U. Rütt, O. Gutowski, A. H. Romero, and F. U. Renner, Chem. Mater. 28, 2941 (2016).

[41] H. B. Michaelson, J. Appl. Phys. 48, 4729 (1977).

[42] K. C. Santosh, X. Ka, C. L. Roberto, and C. Kyeongjae, J. Power Sources 244, 136 (2013).

[43] N. D. Lepley and N. A. W. Holzwarth, Phys. Rev. B 92, 214201 (2015).

[44] M. Nagai and T. Nishio, Solid State Ionics 70/71, 96 (1994).

[45] Y.-H. Hu, I. D. Raistrick, and R. A. Huggins, J. Electrochem. Soc. 124, 1240 (1977).

[46] A. D. Pelton, Bull. Alloy Phase Diagrams 7, 228 (1986).

[47] M. L. Cohen, J. Vac. Sci. Technol. 16, 1135 (1979).

[48] S. Kasamatsu, T. Tada, and S. Watanabe, e-J. Surf. Sci. Nanotech. 8, 93 (2010).

[49] W. Li, Y. Ando, E. Minamitani, and S. Watanabe, J. Chem. Phys. 147, 214106 (2017). 